\title{
Challenging and Changing Lives: The Kwame Nkrumah University of Science and Technology (KNUST) Peer Counseling Program, a Model for Tertiary Institutions
}

Frances Emily Owusu-Ansah ${ }^{2}$, Bernice Ofosuhene S. Peasah ${ }^{1}$, Victoria De-Graft Adjei ${ }^{1}$, Stephen

$$
\begin{gathered}
\text { Jantuah }^{1} \text { and Joana Hackman }{ }^{1} \\
{ }^{1} \text { Counseling Center, Kwame Nkrumah University of Science and Technology } \\
{ }^{2} \text { Department of Behavioral Sciences, Kwame Nkrumah University of Science and Technology } \\
{ }^{1 *} \text { Correspondence: feoansah@gmail.com/ feowusu-ansah.chs@knust.edu.gh }
\end{gathered}
$$

Abstract

This paper is about the KNUST Peer Counsellors Program (KPC); an initiative of the KNUST Counselling Center (KCC). Over the years, the number of Peer Counsellors has increased. Students at the Kwame Nkrumah University of Science and Technology (KNUST) have likewise increased. The aim of the paper was basically to examine the impact of the peer counselling experience on the students who volunteer to be trained and serve as Peer Counsellors. To the best of our knowledge, no study as yet has examined impact of peer counselling among university students in Ghana. Yet, we believe it is a program worth further exploration and development to equip the youth with altruistic values. Reports from the Peer Counsellors affirm the positive impact of the experience on their lives as young people. It projects a viable developmental pathway, career wise, for some of them aside the promotion of own and others wellbeing. Administrative and functional structure of the KPC is described in the paper and recommended as a program for other tertiary institutions to augment formation and education of students.

Keywords: challenging, changing lives, model, tertiary institutions, The KNUST Peer Counseling Program

Citation: Owusu-Ansah, F. E., Peasah, O. S. B., De-Graft Adjei, V., Jantuah, S. and Hackman, J. (2021). Challenging and Changing Lives: The Kwame Nkrumah University of Science and Technology (KNUST) Peer Counseling Program, a Model for Tertiary Institutions. International Journal of Technology and Management Research (IJTMR), Vol. 6 (2): Pp.73-80.

Received: January 3, 2021

Accepted: September 1, 2021 


\subsection{Introduction}

Peer counselling is a process whereby someone listens and provides emotional support to another who shares same status characteristics or demographics (e.g., student to student, patient to patient). Peer counsellors are not professional therapists or professional counsellors. According to Abdullah P., \& Nur F. U. (2021), Peer Counselling is a program specifically designed to provide a learning experience for students in carrying out counselling support services to their colleagues which are expected to increase students' self-confidence in participating in the counsellor's workforce. They are persons who demonstrate care and support to peers through listening and assisting peers to explore thoughts and feelings and provide practical suggestions towards problem solving. Though not a substitute for professional help, they serve as a 'link' or 'bridge' between troubled peers and available professionals and resources (Carr, 1988).

Evidence show that young people tend to seek support and assistance from peers when they are experiencing problems, frustrations, and other life challenges. In a study on the experiences of peer pressure among students in the School of Social Sciences at Makerere University, it was found that if peer counselling is encouraged at various levels of education it will help students learn better skills for managing and coping with their challenges (Nakayemba, 2021). Yet, many young people report that they often do not know what to do to help or do not have the appropriate skills to guide their response. Peer counseling programs, therefore, enhance skills acquisition and knowledge by building on own experiences to boost confidence for more effective peer assistance (Carr, 1988).

Peer counselling was originally introduced in the United States in the 1970s as a means of providing support to persons with disabilities and mental health problems (Nozawa, Ikegami, Michii, Sugano, Ando, Kitamura \& Ogami, 2019). It has expanded to include provision of support to families and patients; being used complementarily for management of non-mental health conditions.

Several studies have shown that peer counselling is a useful and successful compliment to treatment of somatic illnesses like depression (Kohls, Hug, Stahl, Driessen, Roemer, Wollschlaeger, E. \& Rummel-Kluge, 2018), breast cancer and diabetes and health promotion (e.g., breastfeed). When used as an adjunct to patient care, it helps patients' general wellbeing as it enables them to talk about subjectively important, yet unaddressed, issues related to their illness.

In Ghana, peer counselling has been cited in the context of health promotion and evaluation programs (UNICEF Ghana, 2002; Sjaak, 2015) and in education as a means of support for students and parents for better educational and academic performance outcomes at the primary level (Sottie, Dubus \& Sossou, 2013). Some studies have recommended it as an adjunct to support therapy for students dealing with mental health issues (Kugbey, et al., 2015; Ahorsu, et al., 2020). Peer counsellors themselves benefit from the experience of providing support for peers (Carr, 1988). The Carr (1988) study, though nested in a college, was part of a city-wide peer counselling program. However, to the best of our knowledge, relatively less is known about its usefulness and impact among college students who are themselves peer counsellors.

The aims of this paper are twofold: one, to describe the KNUST Peer Counsellors Program, and two, assess its impact on the peer counsellors; hopeful that the preliminary findings would present it as a model for other tertiary institutions in the country and beyond. Given these objectives, the history and structure (including recruitment and 
training) of the KNUST Peer Counsellors Program is presented; as well as the reported benefits and challenges of the program.

\subsection{The KNUST Experience: Peer Counselling, a Need Response}

The Kwame Nkrumah University of Science and Technology (KNUST) is a large state university of over fifty thousand students and a staff capacity of about four thousand. The university operates on a collegiate system being organized into six colleges, aside the Institute of Distance learning (IDL) namely; College of Agriculture and Natural Resources (CANR), College of Art and Built Environment (CABE), College of Engineering (CoE), College of Humanities and Social Sciences (CoHSS), College of Health Sciences (CoHS) and College of Science (CoS).

Each college has a College Counsellor assigned from the KNUST Counselling Center (KCC) which provides psychological support services to students and staff. The Center is staffed by a total of two clinical psychologists and five counselling psychologists. The head of the center combines, also a psychologist, combines clinical practice with administrative responsibilities. The number of students and staff needing psychological counseling assistance far exceeds the center's staff capacity. As part of the efforts to find effective and sustainable ways to serve both students and staff, the KNUST Peer Counseling Program (KPC) became a necessary response.

\subsection{Recruitment and training}

The KNUST Peer Counsellors (KPC) are basically students who volunteer to be trained as skilled helpers so that they can provide psychological and emotional support to other students. They are recruited from the various colleges of the university through using a university-wide bulk messaging system to advertise. While any student may apply to be included in the program, ideally first years, second- or third-year students are preferred to final year students since the latter would not have enough time on campus to benefit from the training and experience of peer counselling. This has been observed from the over five years of peer counselling in KNUST.

Interested students pick up application forms from the KNUST Counselling Center (KCC) and submit by a set deadline. Applications are screened through an interview process conducted and chaired by coordinating counsellors for the program. The interview panel usually consists of two counsellors, an experienced peer counsellor, and an administrative assistant. Aside a sense of commitment and willingness to serve, criteria for selection include right disposition and motivation, affable personality qualities that forms the foundation for building greater interpersonal and listening skills to assist fellow students, an openness to learn, and an average or above average academic performance, determined by cumulative weight average (CWA).

Successful applicants undergo a three-day intensive training program in basic counselling techniques, ethics, communication, and listening skills. In their training, peer counsellors are helped to understand the boundaries of their role as skilled helpers. They are not to engage students beyond what their skills afford. They are equipped with the ethics of the helping profession, particularly issues of confidentiality.

In addition to this initial training, they receive orientation about their roles as peer counsellors and expectations of the program. Throughout an academic year, they receive on-going formative programs as well. To help other students easily identify them, peer counsellors are encouraged to wear their distinctive garb (branded T-shirts and 
the KCC cloth) which they are given during the orientation. Though not full-fledged counsellors, at the end of their training they acquire adequate skills to detect, assist, and or refer students to the counselling center.

\subsection{Roles and expectations}

The primary role of a peer counsellor at KNUST is to be available to other students who may be experiencing personal and emotional difficulties. They are trained is to listen, provide support, and refer students to the counselling center for further assistance, if necessary, after their initial assessment of student's needs and presenting problems.

They are expected to present a log of their counselling activities with fellow students during the semester; having been trained on what and how to write a report. At the end of an academic semester, these reports are collated by the peer counsellors' coordinator who includes the information in the End of Semester Report to the Head of Counselling for inclusion in the Center's Report to Vice Chancellor's Office.

\subsection{Leadership}

The KPC elect own leadership through same process by which other student leaderships of the university (e.g., Students Representative Council, SRC) are elected. Executive positions are publicized and interested peer counsellors apply. These are vetted and a general election is conducted by poll. Existing members of the KPC vote to elect their leaders to serve a one-year tenure.

\subsection{Activities}

There are several activities which the KPC undertake in support of the provision of counselling to students. These include hospital and halls of residence visitations (on and off campus), occasional lecture hall visitations, psychoeducational media programs (as speakers on a university radio program dubbed 'counsellors' corner', and are active participants in all counselling and educational programs organized by the Counselling Center for students. In addition to these, they hold regular general meetings for members during which they monitor their activities and or socialize among themselves to strengthen their network as a group. All their activities (and uniforms) are fully funded by the Counselling Center; having been budgeted for and approved by the Head of Counselling.

Aside their visibility across campus through their presence at the various halls of residence and distinctive garbs, the peer counsellors have a designated office space on campus from which their leadership operates.

\subsection{Incentives}

Though the KPC are not remunerated for the services they offer to other students, being a voluntary program, there are some incentives that keep them motivated. For example, other students accord them due respect for the work they do. Their leadership, executive members, receive a monthly commuting and communication allowances. Graduating peer counsellors, and out-going executives, are awarded certificates for their membership and services rendered. Peer counsellors who distinguish themselves in their work (e.g., as hall or college representatives) also receive citations in addition to their certificates. These awards are given during a well-organized end of academic year certification and dinner ceremony. Many of the peer counsellors are thus motivated to work hard for a meritorious award. 


\subsection{Other Structures, Supervision, and Mentorship}

Reporting lines are clear. The activities of the peer counsellors are supervised by their immediate group counselling mentor who in turn reports to the KPC Coordinating Counsellor. The KPC Coordinating Counsellor is assigned by the KCC Head of Counselling. The Coordinating Counsellor, being in-charge of all that pertains to the peer counsellors, reports to the Head of the Counselling Center.

KPCs are grouped and each group is mentored by a professional full-fledged counsellor of the Counselling Center. Regular meetings are organized by the Mentoring Counsellor for the group during which peer counsellors' supervision, mentoring, and additional cutting-edge professional training inputs are provided. The groups meet periodically (at least once a month) to discuss their challenges and explore solutions. Through this group mentoring, each peer counsellor is helped to reflect on own experiences of being a peer counsellor and to continue to learn toward better service delivery.

The mentorship program operates at two levels - hall and college levels. The university has six traditional halls Unity Hall, Republic Hall, University Hall, Independence Hall, Queens Hall, and Africa Hall. Each of these halls has a Counsellor assigned to it. Peer counsellors are grouped according to their halls of affiliation and come under the Counsellor of that hall. Each hall group elect own officers to coordinate their meetings and activities of the hall members. The mentoring counsellor collaborates with hall administrative staff in her mentoring role and in the organization of seminars or psycho-educative programs for hall residents. At the end of the semester, the hall counsellors submit a report covering all the activities undertaken during the semester to the coordinating counsellor for inclusion in the end of semester report.

At the college level, Peer Counsellors are grouped according to their affiliated colleges, determined by their program of study. There are six colleges at the university as indicated earlier and each assigned own counsellor. The college counsellor supervises the activities of peer counsellors at the college. Therefore, a peer counsellor may be mentored and or supervised by two counsellors if the counsellor at the college is not same at the hall of residence. This arrangement gives peer counsellors varied supervision and mentoring experiences.

The mentoring groupings (hall and college) have several benefits for the on-going formation of the peer counsellors. They have one-on-one contact with Counsellors and frequent meetings in which their questions and concerns are addressed. This way, their detection and referral skills are sharpened. It thus enables them make speedy referrals to counsellors and facilitates submission of reports directly to their counselling supervisors/mentors. Thus, the counsellors are also helped to have a closer contact with peer counsellors for effective mentoring and monitoring of each peer counsellor's activities.

\subsection{Assessing Impact of peer counselling experience - personal and collective}

For the purposes of this paper, KNUST Peer Counsellors were invited to complete a questionnaire about how they perceived their experience as peer counsellors. For ease of administration, the questionnaire was digitized into a google format (web-based). Participation was voluntary though they were encouraged to do so as a reflective exercise. There was no coercion of any sort and no negative consequences to any who refused to participate. Anonymity was ensured since there was no inclusion of any identifying information on the questionnaire. 
Questionnaire consisted of demographics (e.g., gender, age, program of study), years as peer counsellor, level of participation in peer counselling activities, and assessment of impact of the experience as well as challenges.

As at the time of this study, there was a total number of two hundred and forty (240) Peer Counsellors. A total of two hundred and thirty-seven (237) of them voluntarily completed the questionnaire, making an almost hundred percent participation rate. Findings are summarized below.

\subsection{Results}

There were more male Peer Counsellors (162, 68.4\%) relative to the females (75, 31.6\%). Their ages ranged between 18-37 ( $\mathrm{M}=23$; $\mathrm{SD}=9)$ years of age; having been peer counsellors for about a year $(185,78 \%)$ or more than a year $(90,38 \%$.). Majority of them were in the Arts Programs of study (e.g. Business Administration, Economics) and a few in the Sciences (e.g. Physics).

They were all active in their participation of Peer Counsellors' formation and training programs. Many had participated in the recruitment training and orientation (195, 82.3\%). Many others reported regular attendance of their general meetings $(225,94.5 \%)$, mentorship meetings $(141,59.5 \%)$, and capacity building training programs $(140,59.1 \%)$. Hall and hospital visitations were not as well engaged (between 1-3\%). Many (98.3\%) endorsed that their participation in the various training programs had enhanced their skills as peer counsellors. Those skills included communication, listening, and rapport building skills.

Reasons or motivation for being a peer counsellor included a passion to help others (222, 93.7\%), consideration of counselling as a profession in the future (119, 50.2\%), acquisition of counselling skills ( $93,39.2 \%)$, a personal flair for counselling $(77,32.5 \%)$ and possession of listening skills $(185,78.1 \%)$. A few others did not deny the external incentives like the provision of T-shirts/cloth and certificate awards (39, 16.5\%) as their motivation for becoming a peer counsellor. For still others, the opportunity to make new friends, to socialize or to work on own personal issues was the motivation for becoming a peer counsellor $(14,0.56 \%)$.

Challenges reported included a realization of engagement in too many extra-curricular activities that hindered effective functioning as peer counsellors for some of them (48, 27.5\%). Some others wished they had more clients $(47,19.8 \%)$. A few felt fearful that giving too much time to peer counselling would negatively affect their academic performance $(24,10.2 \%)$. However, for many of them the academic concerns and constraining extracurricular activities were not problematic issues (136, 43\%; 179, 75.5\% respectively). Instead, many endorsed that even the lack of monetary remuneration did not deter or water down their motivation to serve as peer counsellors $(215,90.7 \%)$. All $(237,100 \%)$ affirmed that the experience of being a peer counsellor has positively impacted their lives. Many agreed that they have experienced personal growth in varied ways. Excerpts of responses are:

"It has made me understand how complex bumans are and how vigilant you have to be when dealing with people. Moreover, it has also made me understand life better; how little issues lead to the unthinkable".

"My ability to form rapport and ability to communicate with other people has improved".

"My self-confidence is better"

"Shaped my ideologies and given me knowledge". 
They were also given the opportunity to suggest ways of improving the Peer Counselling Program at KNUST. Some recommended additional recruitment. Others spoke about the need for more awareness creation efforts. While some noted the following:

"I think a day can be set aside, maybe once or twice in a month, where authorities of KPC can bave one-on-one meeting with the individual peer counsellors to bear them out of their grievances".

"We should improve upon halls and hostels visitation by consistently visiting our clients."

\subsection{Conclusion}

This preliminary study assessed the impact of peer counselling on the peer counsellors at the KNUST campus. It provides germinal insights for further reflection and research. Findings show that peer counselling has positive impact and adds to the personal development and wellbeing of young persons; corroborating previous studies in related research areas. It was interesting to find that many peer counsellors were not motivated by money. This is a good thing. In today's world where many young people are desperately pursuing money and self-interests, it is refreshing to see university students altruistically and voluntarily choosing service of others as an option worthy of pursuit. Peer counsellors' lives are not only positively impacted, their service of others also promote wellbeing; for themselves and those they serve. The values acquired enhance their lives as well. We believe that this is a step in the right direction.

Education is both formative and informative; the formative component being more important, yet more difficult. Tertiary education, must of necessity, include programs that challenge the youth towards greater self-awareness and self-transcendence. Programs that invite students to volunteer their services for the wellbeing of others is a good start.

It is for these reasons that the KNUST Peer Counsellors Program is recommended for consideration and implementation at other tertiary institutions in the country and beyond. It's outlined structures and activities can be improved upon. The human race will reap the benefits and be better for it.

\section{References}

Abdullah P., \& Nur F. U. (2021) The Need Analysis of Peer Counseling Program to Enhance Self-Efficacy to be a Counsellor

Ahorsu, D.K., Ajaotto, E.S. Yeboah, F.A. \& Opoku, Y. (2020). Mental health challenges in academia: comparison between students of the various educational levels in Ghana. Journal of Mental Health, https://doi.org/10.1080/09638237.2020.1739253.

Burns, J., \& Birrell, E. (2014). Enhancing early engagement with mental health services by young people. Psychology research and behavior management, 7, 303.

Carr, R. A. (1988). The city-wide peer counselling program. Children and youth services Review, 10(3), 217-232.

Fukkink, R. (2011). Peer counseling in an online chat service: A content analysis of social support. Cyberpsychology, behavior, and social networking, 14(4), 247-251.

Kohls, E., Hug, J., Stahl, M., Driessen, P., Roemer, C., Wollschlaeger, E., ... \& Rummel-Kluge, C. (2018). Peer counselling in depression care: A pilot study in a psychiatric inpatient setting. Psychiatry research, 270, 698-704. 
Kugbey, N., Osei-Bonsu, S., \& Atefoe, E. A. (2015). The influence of social support on the level of depression, anxiety \& stress among students. Journal of Education and Practice, 6(25), 135-140.

Nakayemba, J. D. (2021). Experiences of Peer Pressure Among Students in the School of Social Sciences at Makerere University. http://196.43.133.120/handle/20.500.12281/9889

Nozawa, H., Ikegami, K., Michii, S., Sugano, R., Ando, H., Kitamura, H., \& Ogami, A. (2019). Peer counselling for mental health in young people-Randomized clinical trial-. Mental Health \& Prevention, 14, 200164.

Rø, K. I., Veggeland, F., \& Aasland, O. G. (2016). Peer counselling for doctors in Norway: A qualitative study of the relationship between support and surveillance. Social science \& medicine, 162, 193-200.

Rummel-Kluge, C., Stiegler-Kotzor, M., Schwarz, C., Hansen, W. P., \& Kissling, W. (2008). Peer-counseling in schizophrenia: patients consult patients. Patient education and counseling, 70(3), 357-362.

Sjaak van der Geest (2015). Wisdom and counselling: A note on advising people with HIV/AIDS in Ghana. African Journal of AIDS Research, 14, Issue 3.

Sottie, A. C., Dubus, N., \& Sossou, M-A. (2013). Enchancing student outcome through mentoring, peer counselling and parental involvement. Prospects, 43, 377-391.

UNICEF Ghana (2002). Evaluation of HIV/AIDS prevention through peer education, counselling, health care, training and urban refugees in Ghana. Evaluation \& program planning, 25(4), November, 409-420. 